\begin{tabular}{|c|c|c|c|}
\hline $\begin{array}{l}\text { FEB } 172000 \\
\text { STA } 4\end{array}$ & ENGINEERING DATA TRANSMITTAL & $S$ & 1. EDT 618046 \\
\hline
\end{tabular}

\begin{tabular}{|l|l|}
\hline $\begin{array}{l}\text { 2. To: (Recelving Organization) } \\
\text { Distribution }\end{array}$ & $\begin{array}{l}\text { 3. From: (Originating Organization) } \\
\text { Fluor Federal Services }\end{array}$ \\
\hline $\begin{array}{l}\text { 5. Proj./Prog./Dept./Div.: } \\
\text { Az-101 Mixer Pump Test }\end{array}$ & $\begin{array}{l}\text { 6. Design Authority/Design Agent/Cog. Engr.: } \\
\text { GR Tardiff/SG Romero/WD Winkelman }\end{array}$ \\
\hline
\end{tabular}

8. Originator Remarks:

This EDT is for Document Approval and Release

11. Recelver Remarks:

11A. Design Baseline Document? $\bigcirc$ Yes

O No

\section{Related EDT No.: \\ 7. Purchase Order No: \\ $\mathrm{N} / \mathrm{A}$}

9. Equip./Component No::

AZ-101 Mixer Pump DAS 10. System/Bldg./Facility:

$$
\text { 241-AZ }
$$

12. Major Assm. Dwg. No.:

H-2-78870, SH-1, Rev. 2 13. Permit/Permit Application No.:

$\mathrm{N} / \mathrm{A}$

14. Required Response Date:

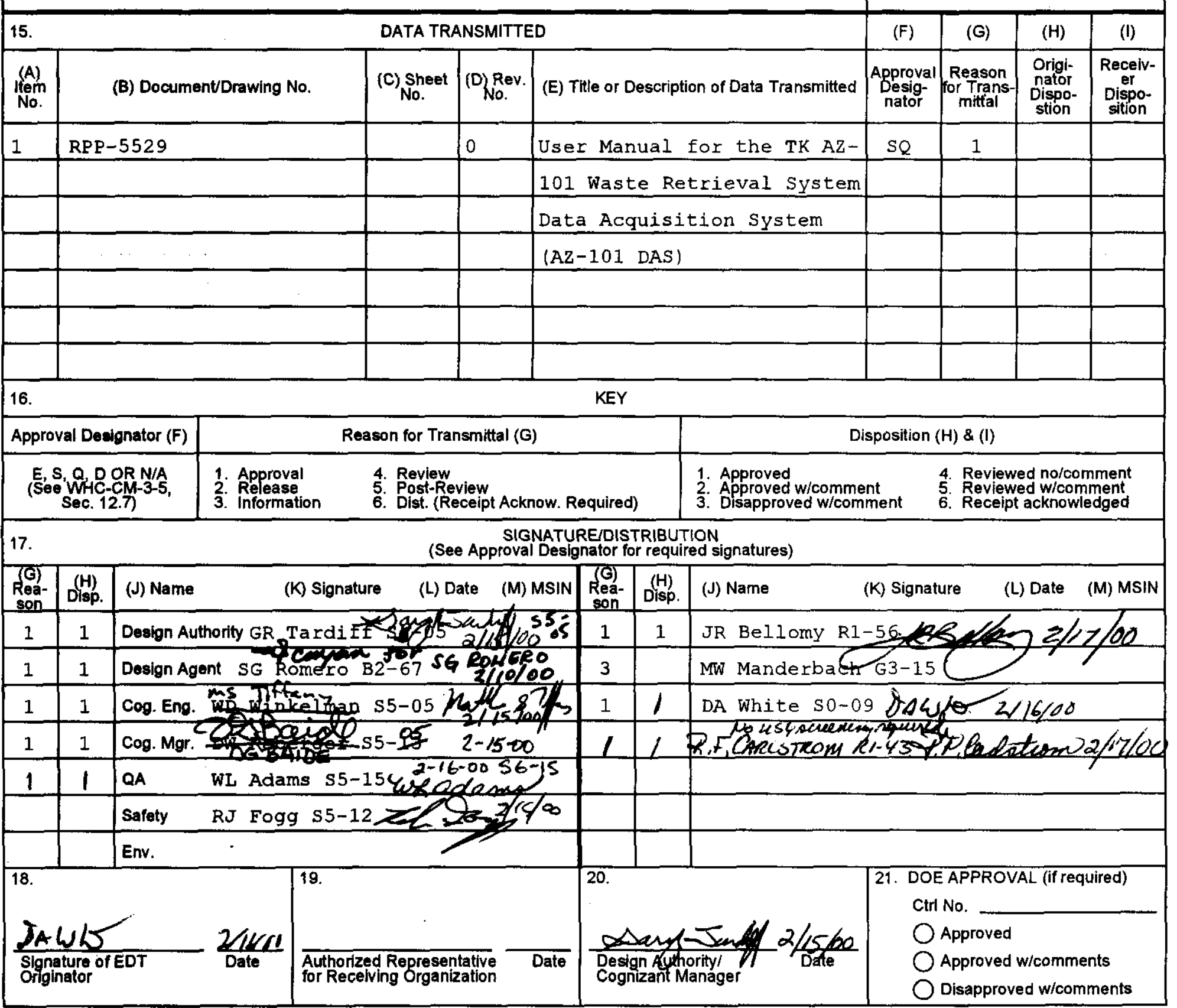




\title{
USER MANUAL FOR THE AZ-101 DATA ACQUISITION SYSTEM (AZ-101 DAS)
}

\author{
D. D. Brayton \\ FLUOR FEDERAL SERVICES \\ Richland, WA 99352 \\ U.S. Department of Energy Contract DE-AC06-96RL13200

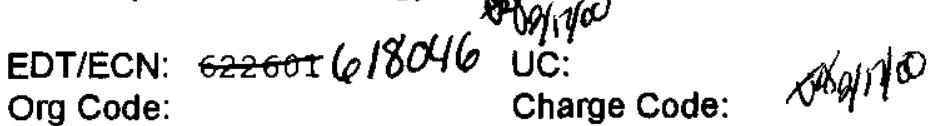 \\ B\&R Code: $\quad$ Total Pages: $2 \$ 4$
}

Key Words: User manual for the TK AZ-101 Waste Retrieval System Data Acqu isition system

Abstract: User manual for the TK AZ-101 Waste Retrieval System Data Acquis ition System

*Windows NT is a registered trademark of Microsoft. Corporation. Microsoft is a registered trademark of Microsoft Corporation.

TRADEMARK DISCLAIMER. Reference herein to any specific commercial product, process, or service by trade name, trademark, manufacturer, or otherwise, does not necessarily constitute or imply its endorsement, recommendation, or favoring by the United States Government or any agency thereof or its contractors or subcontractors.

Printed in the United States of America. To obtain copies of this document, contact: Document Control Services, P.O. Box 950, Mailstop H6-08, Richland WA 99352, Phone (509) 372-2420; Fax (509) 376-4989.
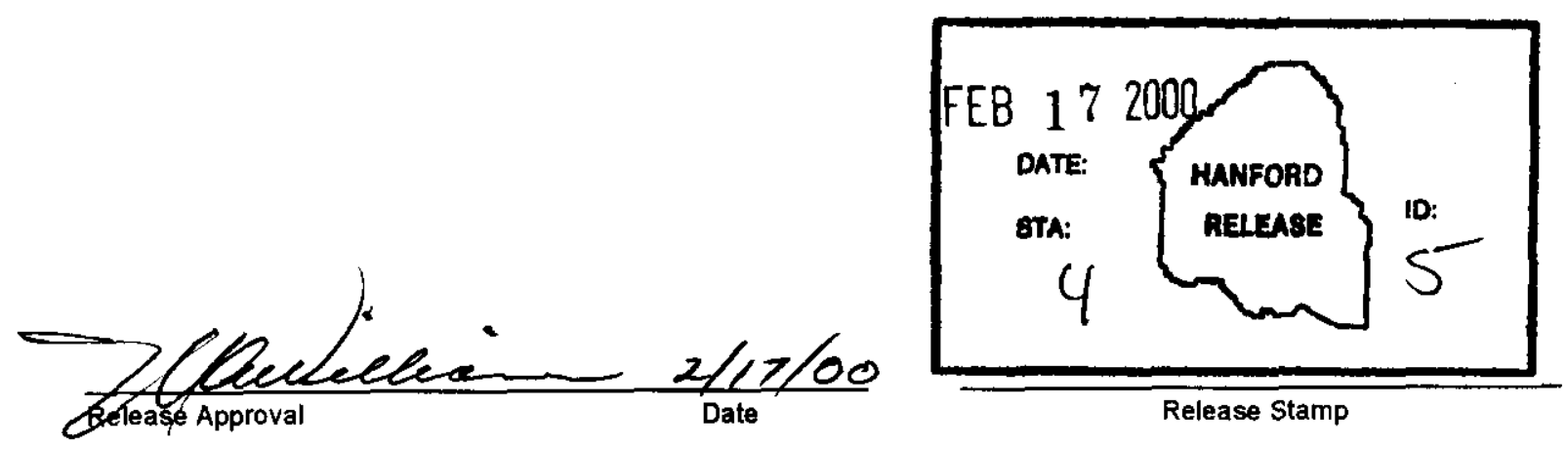


\section{USER MANUAL}

\section{FOR THE}

\section{AZ-101 \\ DATA ACQUISITION SYSTEM}

\section{(AZ-101 DAS)}

\section{Fluor Federal Services (FFS) (CCAD SI Team)}

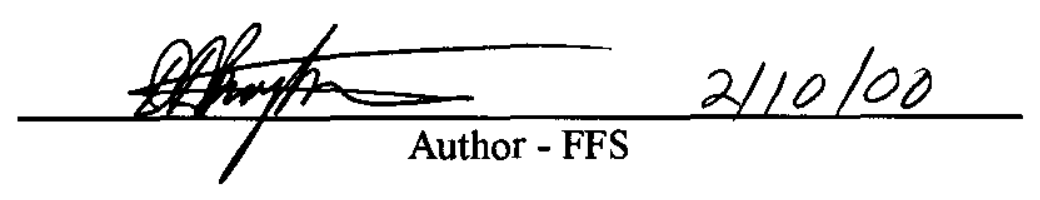

$\frac{\text { Eruin Pacyan } 2 / 10 / 00}{\text { Checker - FFS }}$

hub haudulade y/o/so Project Manager - FFS

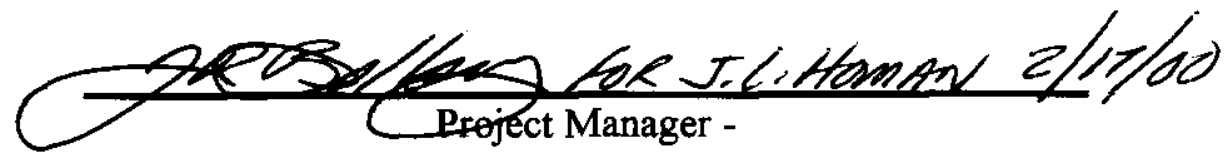




\section{TABLE OF CONTENTS}

Section

1.0 INTRODUCTION................................................................................................................... 1

1.1 User Manual Overview........................................................................................................ 1

1.2 AZ-101 DAS System Overview ........................................................................................ 1

1.3 AZ-101 DAS Hardware and Software ............................................................................ 3

1.4 Security ..................................................................................................................... 3

1.5 Acronyms and Definitions.................................................................................................. 3

2.0 AZ-101 DAS OPERATING INSTRUCTIONS........................................................................... 4

2.1 Starting Up the AZ-101 DAS HMI PC ..................................................................... 4

2.1.1 Power On the HMI PC .......................................................................................... 4

2.1.2 Restart the HMI PC........................................................................................... 4

2.2 Navigating Screens and General Commands ............................................................... 5

2.2.1 Windows Look and Feel.................................................................................... 5

2.2.2 Folder Tabs and Icons ................................................................................. 6

2.2.3 Data Point Display ................................................................................................ 7

2.3 Maintaining User Names and Passwords ................................................................ 8

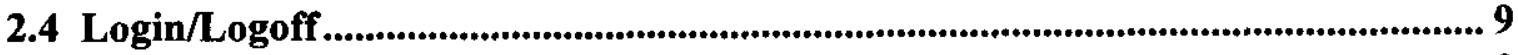

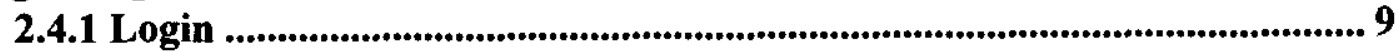

2.4.2 Log Out .............................................................................................................. 9

2.5 Viewing Data ................................................................................................................ 10

2.5.1 Overview .................................................................................................................. 10

2.5.2 Pump Status...................................................................................................... 11

2.5.3 Strain ..................................................................................................................... 12

2.5.4 Temp Profile ............................................................................................................ 13

2.5.5 Micon Data ............................................................................................................. 15

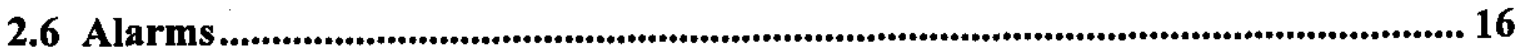

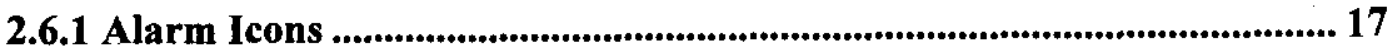

2.6.2 Acknowledging Alarms ...................................................................................... 17

2.7 Trending Data ............................................................................................................... 19

2.7.1 Single Point Trend ............................................................................................... 19

2.7.2 Excel Trend Sets................................................................................................... 21

2.8 Shutting Down....................................................................................................... 22 


\section{User Manual for AZ-101 Data Acquisition System}

\subsection{INTRODUCTION}

\subsection{User Manual Overview}

The purpose of this document is to describe use of the AZ-101 Data Acquisition System (AZ-101 DAS).

The AZ-101 DAS is provided to fulfill the requirements for data collection and monitoring as defined in Letters of Instruction (LOI) from Numatec Hanford Corporation (NHC) to Fluor Federal Services (FFS). For a complete description of the system, including design, please refer to the AZ-101 DAS System Description document, RPP-5572.

\subsection{AZ-101 DAS System Overview}

The primary function of the AZ-101 DAS is to provide monitoring and data acquisition of key parameters in the mixing of radioactive waste stored in tank 241-AZ-101. The AZ-101 DAS display is divided into six main (M) screens and several sub-screens (S), as outlined below:

\begin{tabular}{|c|c|c|}
\hline $\mathbf{M}$ & \multicolumn{2}{|c|}{ OVERVIEW } \\
\hline M & \multicolumn{2}{|c|}{ PUMP STATUS } \\
\hline M & \multicolumn{2}{|c|}{ STRAIN } \\
\hline M & \multicolumn{2}{|c|}{ TEMP PROFILES } \\
\hline & $\mathbf{S}$ & Tank AZ-101 Airlift Circulator Temperatures \\
\hline & $\mathbf{S}$ & Tank AZ-101 Insulation Concrete Temperatures \\
\hline & $\mathbf{S}$ & Tank AZ-101 Sludge (Drywell) Temperatures \\
\hline & $\mathbf{S}$ & Tank AZ-101 Tank Foundation Temperatures \\
\hline & $\mathbf{S}$ & Tank AZ-101 Tank Dome Temperatures \\
\hline & $\mathbf{S}$ & Tank AZ-101 Tank Wall Temperatures \\
\hline & $\mathbf{S}$ & Tank AZ-101 Profile Trees Temperatures \\
\hline $\mathbf{M}$ & \multirow{2}{*}{\multicolumn{2}{|c|}{$\begin{array}{l}\text { MICON DATA } \\
\text { ALARMS }\end{array}$}} \\
\hline & & \\
\hline
\end{tabular}

Process control is outside of the scope of the AZ-101 DAS system. 

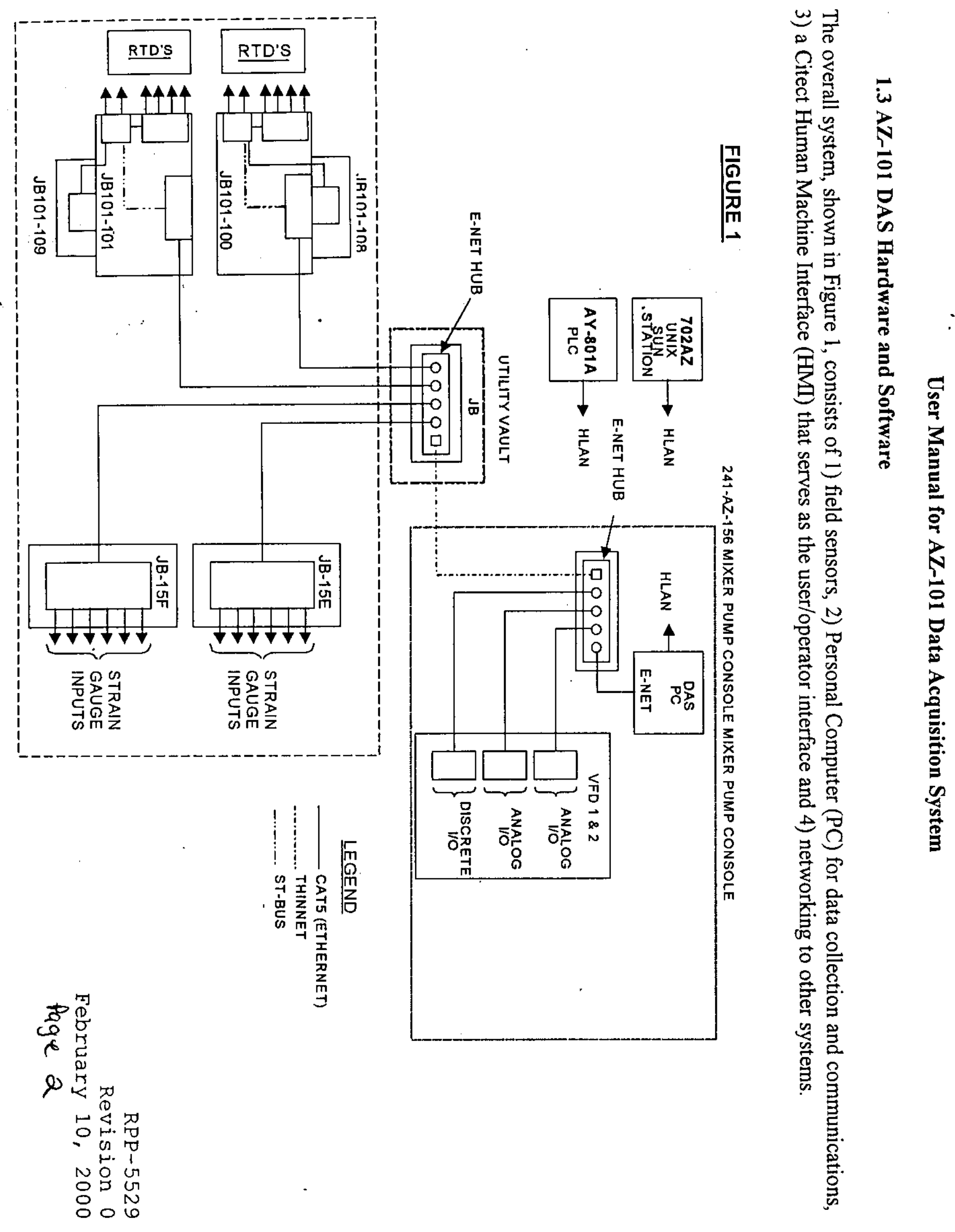


\section{User Manual for AZ-101 Data Acquisition System}

With this DAS architecture, future modifications can be made to allow any PC on HLAN running the same HMI software to view live process data and alarms at any location within the Hanford site, as authorized.

\subsection{Security}

The AZ-101 DAS shall be installed on authorized user machines only. Access control is the responsibility of the system administrator and appropriate users.

Several levels of access control are available, and are assigned to each system user by the system administrator prior to system use. These levels are described in Section 2.3.

\subsection{Acronyms and Definitions}

ALARA $\quad \underline{A} \underline{\text { Low }} \underline{\text { As }} \underline{\text { Reasonably }}$ Achievable

Child Screen A type of AZ-101 DAS screen accessible only from a parent screen.

Data Box Provides a data values \& alarm annunciation on parent and child screens.

DAS Data Acquisition System--Based on a PLC/PC architecture to collect field data and provide a full user interface or HMI to display, manipulate, save and print data.

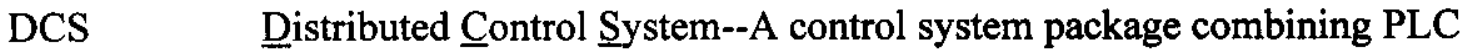
and HMI functionality, with multiple autonomous controllers and interfaces.

HMI $\quad$ Human $\underline{\text { Machine Interface-Provides a PC-based graphical operator }}$ interface.

Icon Graphical symbol representing an HMI function that will be performed.

Parent One of five top level screens in the AZ-101 DAS accessible by selecting a Screen folder tab.

PLC Programmable Logic $\underline{\text { Controller }}$

PC $\quad \underline{P}$ ersonal $\underline{\text { Computer }}$ 


\section{User Manual for AZ-101 Data Acquisition System}

\subsection{AZ-101 DAS OPERATING INSTRUCTIONS}

This user manual will provide instructions for performing the following AZ-101 DAS functions:

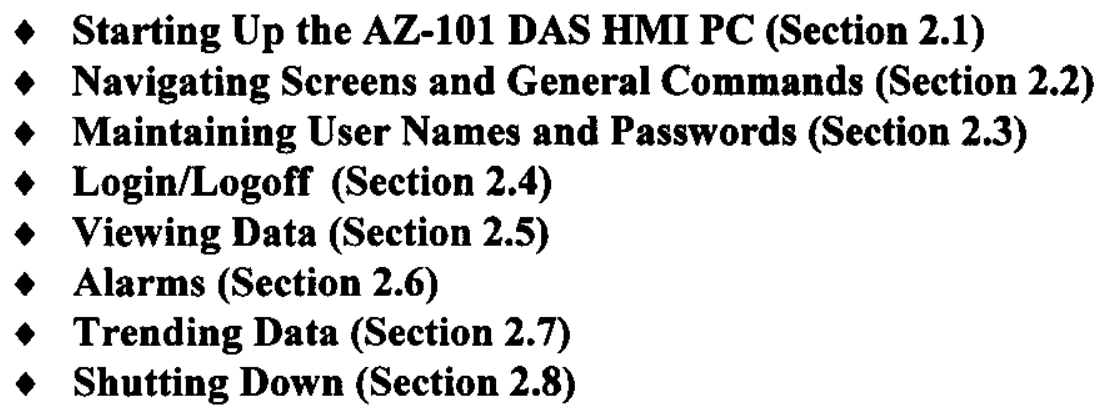

\subsection{Starting Up the AZ-101 DAS HMI PC}

There are two scenarios for starting the AZ-101 DAS application. Otherwise the properly installed, powered-on AZ-101 DAS is ready for use.

\subsubsection{Power On the HMI PC}

If the AZ-101 DAS HMI PC is powered off, then the power switch of the HMI PC needs to be turned on. This will automatically start the AZ-101 DAS application resulting in the display of the start-up screen, "OVERVIEW" shown in Figure 2. Note that the screens shown indicate "Simulator". This would indicate you are running the CD-ROM trainer, which has identical screens to the actual DAS, except for this word.

\subsubsection{Restart the HMI PC}

You MUST have proper authorization to perform the reboot of the AZ-101 DAS HMI PC. Contact the System Cognizant Engineer for authorization, or contact the Shift Manager on duty off-hours.

If the AZ-101 DAS HMI PC is locked up (digital clock does not update seconds) then press the Ctrl-Alt-Delete buttons on the keyboard at the same time. A Windows NT Security box appears. Select the Windows NT option to Shut Down, then select Shutdown and Restart and click OK. This will automatically restart the AZ-101 DAS application, resulting in the display of the startup screen, "OVERVIEW" shown in Figure 2. There are also PLC "heartbeats" that flash to indicate communication with systems. If steady, communication has ceased. 
User Manual for AZ-101 Data Acquisition System

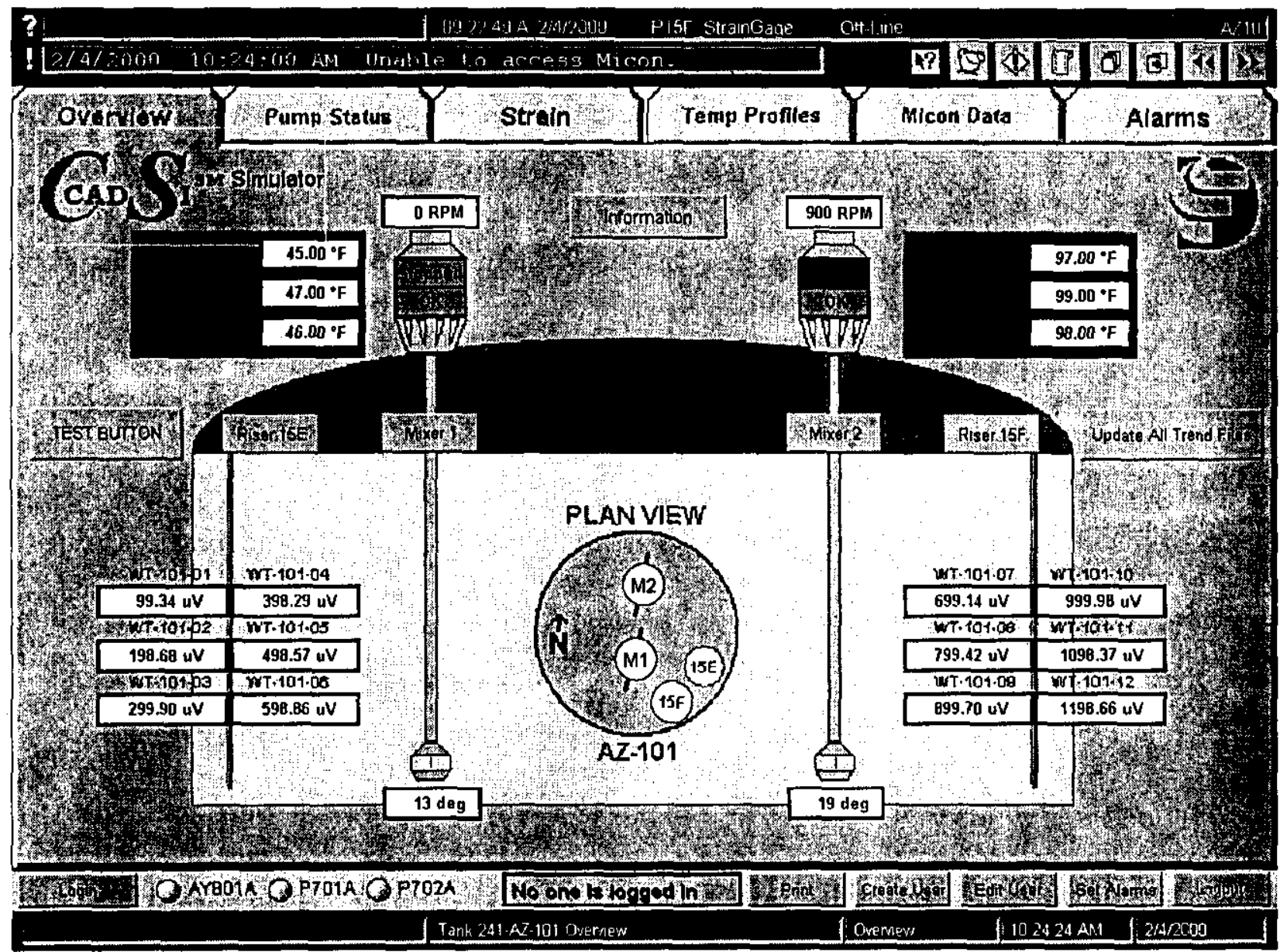

FIGURE 2

\subsection{Navigating Screens and General Commands}

\subsubsection{Windows Look and Feel}

The AZ-101 DAS is designed to be operated with a standard Windows look and feel. That is, the operating system is Windows NT, a pointer (e.g., mouse) is used to navigate, and clicking the mouse buttons on icons are used to initiate pre-defined functions. Where necessary to save files, a standard Windows dialog box is used. 


\section{User Manual for AZ-101 Data Acquisition System}

Function key buttons may also be used, in combination with the mouse. AZ-101 DAS function key button commands are as found in Table 1 .

\begin{tabular}{|c|c|c|}
\hline \multicolumn{3}{|c|}{ TABLE 1-General Function Keys For The AZ-101 DAS } \\
\hline Key & Name & Description \\
\hline $\begin{array}{l}\text { Fl or } \\
\text { Home }\end{array}$ & Overview & Displays the RPP DAS PROCESS OVERVIEW screen. \\
\hline F2 & $\begin{array}{l}\text { Pump } \\
\text { Status }\end{array}$ & Displays the Mixer Pumps STATUS screen. \\
\hline F3 & Strain & $\begin{array}{l}\text { Displays the Tank } 24 \mathrm{l}-\mathrm{AZ}-101 \text { thermocouple tree stress/strain } \\
\text { information screen. }\end{array}$ \\
\hline F4 & $\begin{array}{c}\text { Temp } \\
\text { Profiles }\end{array}$ & Displays the Tank 241-AZ-101 Temperature Profile screens. \\
\hline F5 & Micon Data & Displays the Tank 241-AZ-101 HVAC Screen. \\
\hline F6 & Alarms & Displays the ALARMS screens. \\
\hline F7 & $\begin{array}{c}\text { Hardware } \\
\text { Alarm }\end{array}$ & Displays the Hardware Alarm Screen. \\
\hline F8 & $\begin{array}{c}\text { Alarm } \\
\text { Summary } \\
\end{array}$ & Displays the Alarm Summary Screen. \\
\hline F9 & Login & Displays the Login Screen. \\
\hline F10 & Information & Displays the Information Screen. \\
\hline F12 & ACK & Acknowledges all active alarms on the current screen \\
\hline
\end{tabular}

\subsubsection{Folder Tabs and Icons}

The AZ-101 DAS is setup with several screens organized with folder tabs. These folder tabs are organized horizontally. Associated screens (e.g., OVERVIEW, PUMP STATUS, etc.) are referred to as the parent screens. Sub-screens entered from a parent screen are referred to as a child screen. Refer to Figure 2. 


\section{User Manual for AZ-101 Data Acquisition System}

In addition to the folder tabs are a horizontal line of icons in the top-right hand corner (see Figure 3):

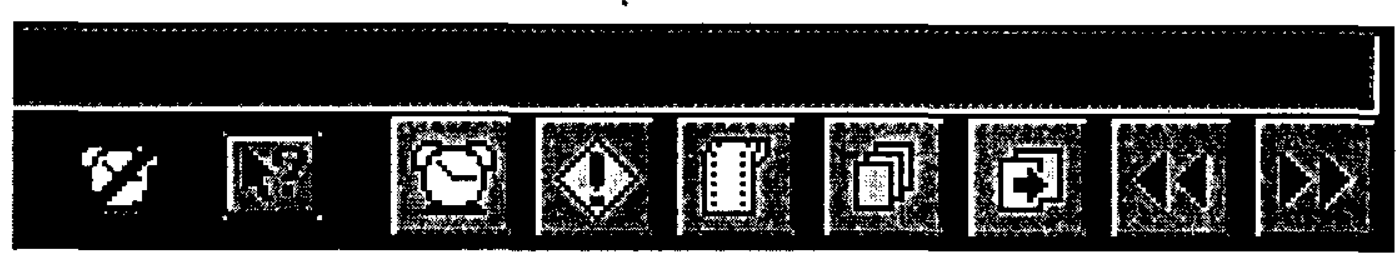

FIGURE 3

From Left to Right:

Alarm Clock w/Slash-Out Icon-appears if any alarms are disabled.

Question Mark Icon--toggles display of tool tips (limited help text) for screen buttons and symbols

Alarm Clock Icon--switches to the "ALARMS" folder tab.

Exclamation Point in a Diamond Icon--displays the Hardware Alarms screen (i.e., communication failures).

Scroll of Paper --displays the Alarm Summary screen.

Multiple Layers of Paper--displays Page Select window, which allows user to select a screen without using folder tabs or icons.

Two Layers of Paper with Horizontal Arrow--displays previous screen.

Arrow--left to go to previous parent screen, right to go to next parent screen.

For more information on Alarm Icons, see section Acknowledging Alarms.

\subsubsection{Data Point Display}

Data points on each screen are displayed on a plain white background box (data box) with engineering units displayed adjacently. If an alarm is present the color background of the box changes to either yellow or red, and flashing or steady according to acknowledgment status. Some groups of data, depending on the screen displayed, are available via a button. 


\section{User Manual for AZ-101 Data Acquisition System}

\subsection{Maintaining User Names and Passwords}

The AZ-101 DAS system has five levels of user security as outlined in Table 2, which also lists the user groups and their access to different types of functions.

A user may not quit the DAS or start other programs unless his/her access group is permitted to do so. The AZ-101 DAS program is started on reboot.

The "Create User" and "Edit User" buttons from the "OVERVIEW" screen allow authorized personnel to create and edit user profiles.

\begin{tabular}{|c|c|c|}
\hline \multicolumn{3}{|c|}{ Table 2--User Groups and Accessible Functions } \\
\hline Level & User Group & Accessible Functions \\
\hline 1 & Not Logged In & Monitor data and alarms only. \\
\hline 2 & Operator & $\begin{array}{l}\text { Monitor all data and alarms, acknowledge } \\
\text { alarms, view alarm setpoints, change trend } \\
\text { configurations. }\end{array}$ \\
\hline 3 & Shift Supervisor & $\begin{array}{l}\text { All Operator functions plus enable/disable } \\
\text { alarms, change alarm setpoints with } \\
\text { concurrence of cognizant engineer. }\end{array}$ \\
\hline 4 & Remote Manager Node & Monitor Data and Alarms \\
\hline 5 & System Engineer & $\begin{array}{l}\text { All Shift Supervisor functions plus the ability } \\
\text { to make software changes in the PLC and } \\
\text { HMI PC add users and edit user security } \\
\text { levels. }\end{array}$ \\
\hline
\end{tabular}

Note: Use of the term System Engineer refers to a DAS security access level only, not to job titles or other functions. 


\section{User Manual for AZ-101 Data Acquisition System}

\section{$2.4 \operatorname{Login} / \operatorname{Logoff}$}

The AZ-101 DAS user, per Table 2, needs to Login/Logoff only to perform the additional tasks allowed to their user group. To receive a login user name and password contact the system administrator (typically the cognizant engineer or appointee).

\subsubsection{Login}

To Login, select the "Login" button, which is available on any Parent Screen (bottom left), and the Login Form is then displayed (Figure below). To complete login, enter user name and password. If either is incorrect the form continues to be displayed until correct or canceled. Once a user is logged in, the Current User is displayed at the bottom of the screen, in the middle. To cancel, select "Cancel".

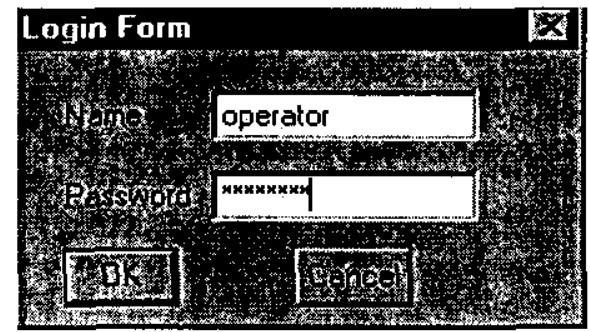

FIGURE 4

\subsubsection{Log Out}

To log out, no confirmation is needed. Select the "Logout" button, which is available on any Parent Screen (bottom right). No other action is required. Once a user is logged out, the Current User display shows that "No one is logged in". 


\section{User Manual for AZ-101 Data Acquisition System}

\subsection{Viewing Data}

Users have several options for viewing data. The following parent screens provide process related point data:

"OVERVIEW" (Figure 2)

"PUMP STATUS" (Figure 5)

"STRAIN" (Figure 6)

"TEMP PROFILES" (Figure 7)

"MICON DATA" (Figure 8)

"ALARMS" (Figure 9)

Each parent screen has a "Print" button that allows the screen to be printed. The "Set Alarms" button allows available alarm information to be modified by authorized personnel. Select this button, position cursor over the value of the tag you wish to modify. A yellow box with the value you type will display and if you press enter, this value is accepted.

\subsubsection{Overview}

This screen (Figure 2) shows the tank in the mixing process. If the process is active the pump process is animated. The primary data available are:

$>$ Mixer Pump Activation

$>$ Mixer Pump Speed (RPM)

$>$ Pump Nozzle Angle

$>$ Strain Gauge Measurement

$>$ Stator Winding Temperature

When the mouse cursor is positioned and clicked on the "Mixer 1", "Mixer 2", "Riser 15E", or "Riser 15F" the associated Parent Screen is displayed. 


\subsubsection{Pump Status}

This screen (Figure 5) shows Mixer Pumps M1 and M2 status. The primary data available are:

$>$ Water Pressure

$>$ Upper and Lower Vibration

$>$ Pump Run Time (total and current)

$>$ Nozzle Orientation

$>$ Temp Upper and Lower Bearings

$>$ Mixer Voltage

$>$ Mixer Current

$>$ Mixer Speed

$>$ Mixer Frequency

$>$ Bearing Water Filter Differential Pressure

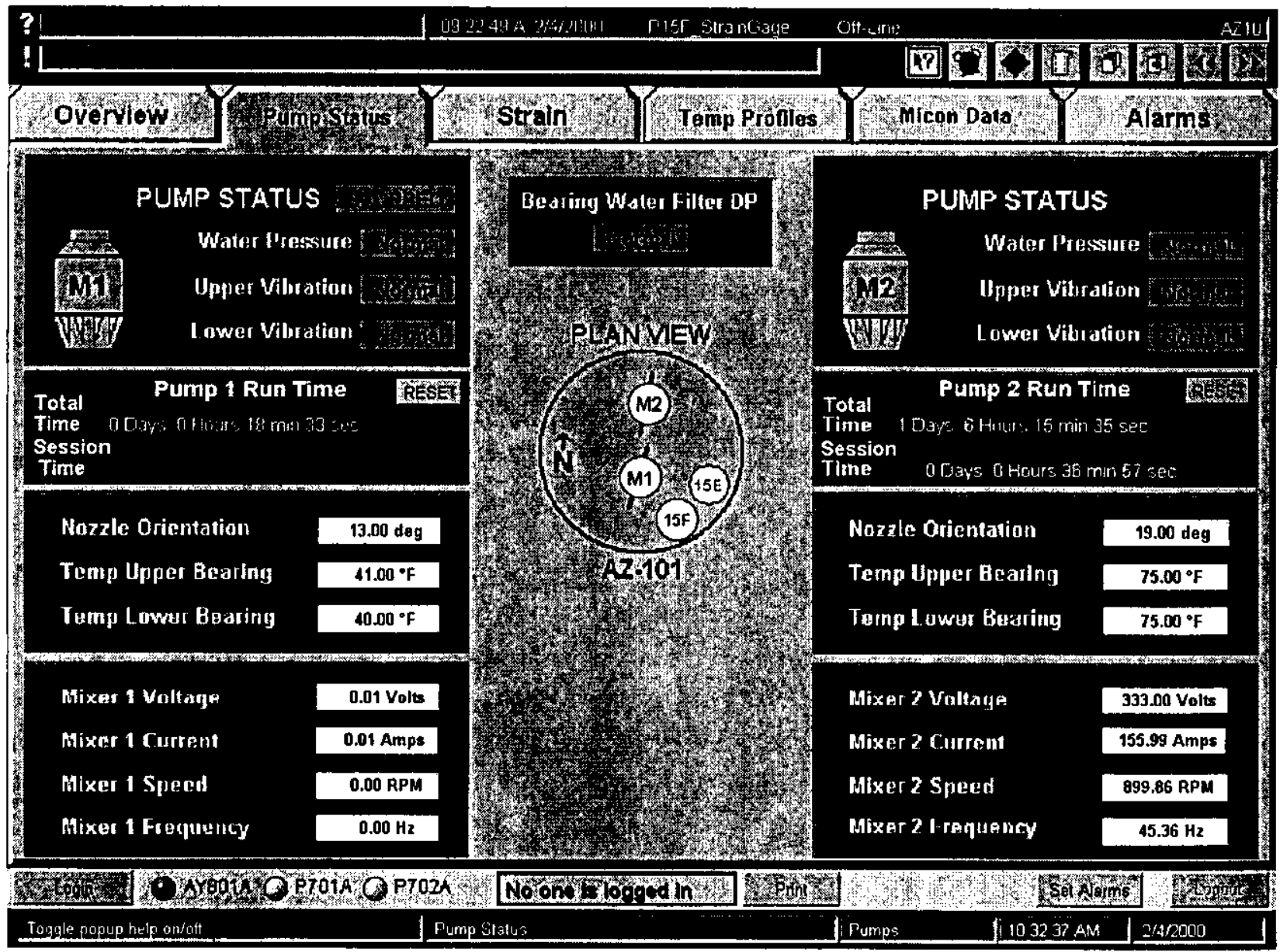

FIGURE 5 
To reset the Total Time display, press the "RESET" button. A display will ask if you are sure. Click "Okay" to reset, or "Cancel". This action resets the counter, or if the pump is not running, blanks the display. The Session Time display will reset everytime the pump is stopped.

\subsubsection{Strain}

This screen (Figure 6) displays the strain gauge data. The gauge monitors the response to forces exerted on the temperature profile trees inserted into the tank through risers $15 \mathrm{E}$ and $15 \mathrm{~F}$.

The primary data available are:

$>$ Strain Gauge Measurements

$>$ Mixer Pump Nozzle Orientation

$>$ Strain Gauge Excitation Voltage

$>$ Temperature at Junction Box

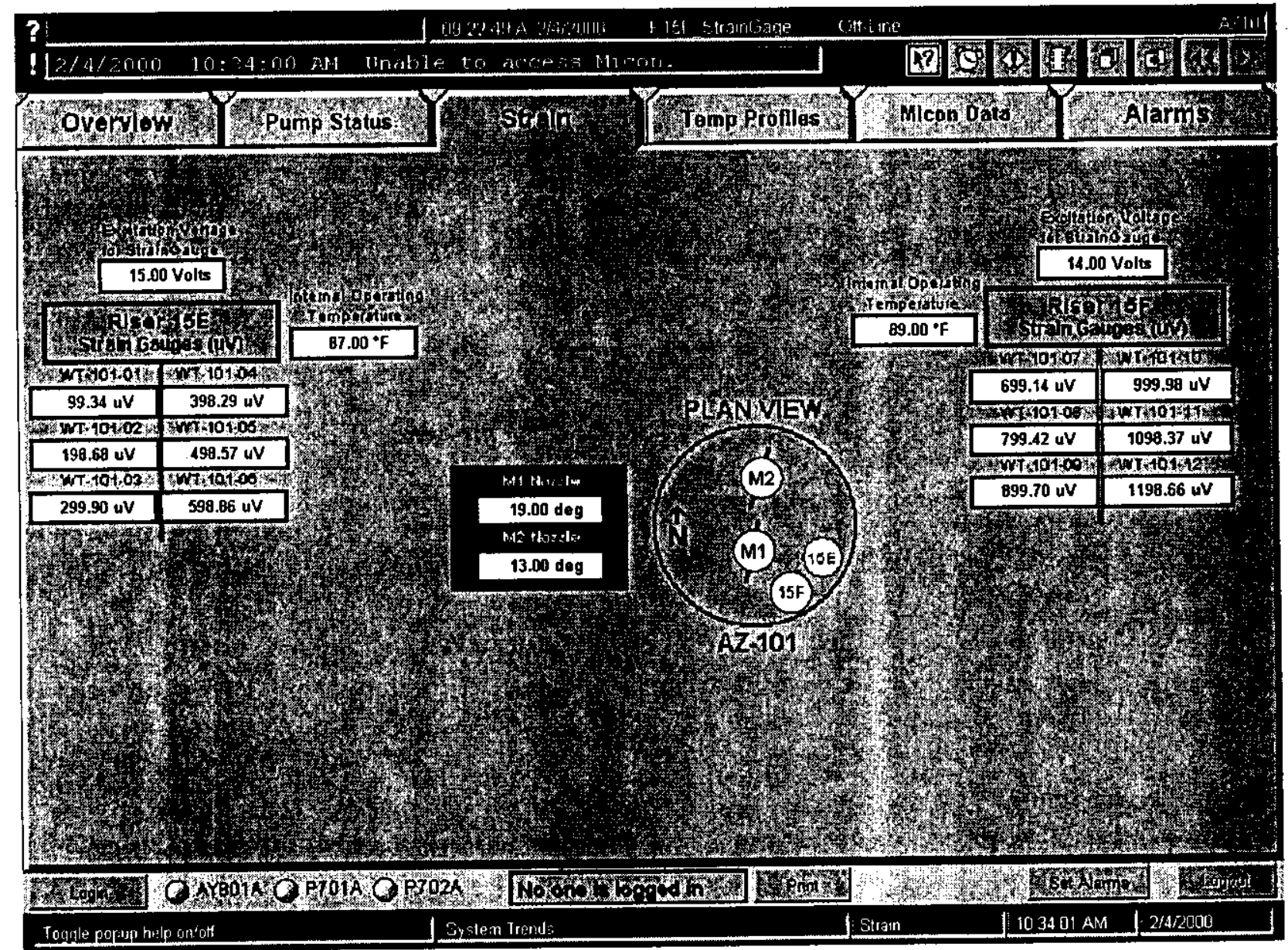

FIGURE 6 


\subsubsection{Temp Profile}

Selecting the "TEMP PROFILES" tab displays tank temperature data as shown in Figure 7. Selecting the following buttons to display the selected temperature data:

$>$ Airlift Circulator

$>$ Insulation Concrete

$>$ Sludge (Drywell)

$>$ Tank Foundation

$>$ Tank Dome

$>$ Tank Wall

$>$ Profile Trees

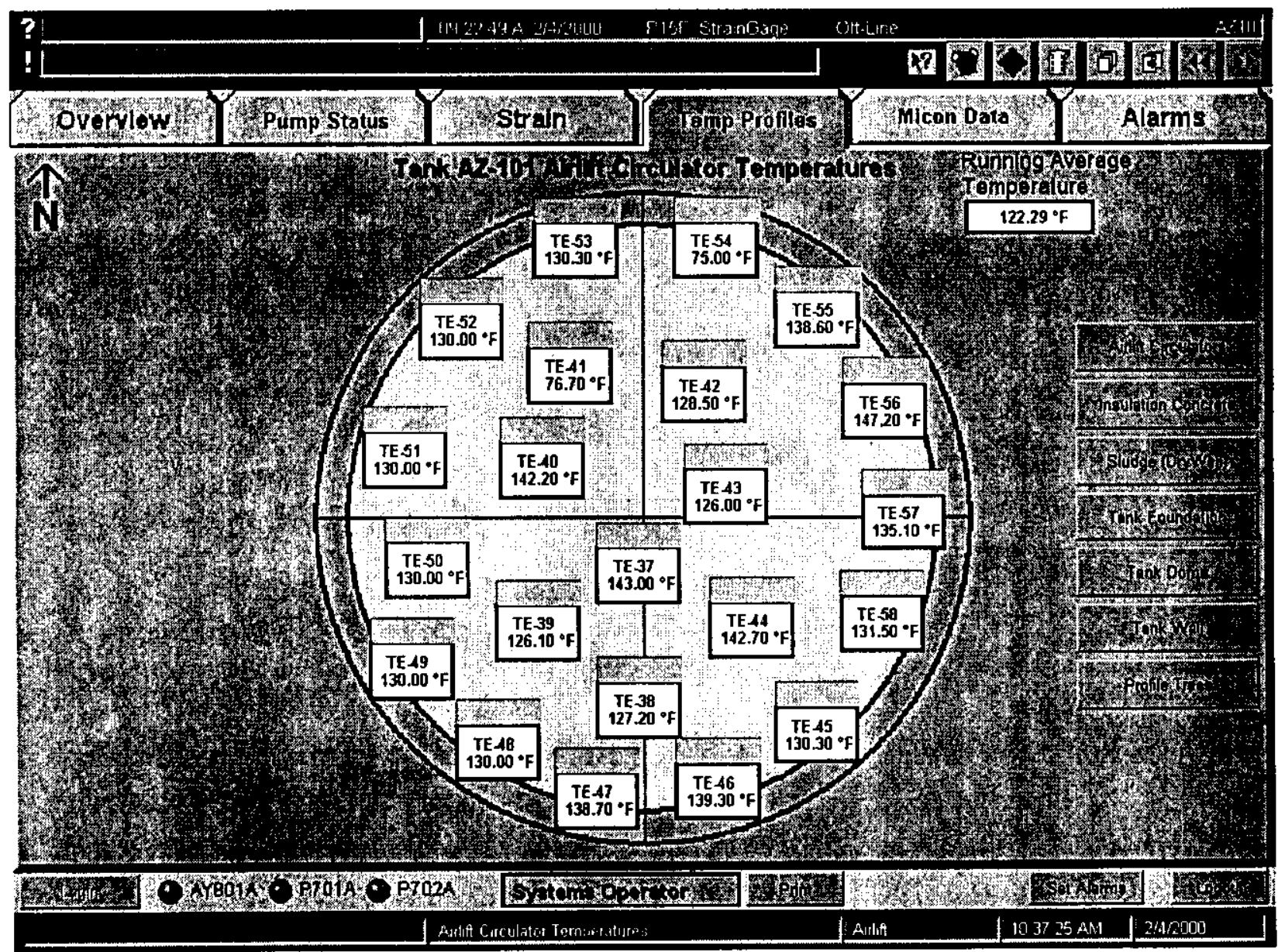

FIGURE 7 
Each individual temperature element, when selected with the mouse, will display a trending chart of its associated data. These charts function the same as described in section 2.7.1 Single Point Trend. The average of selected temperature data is shown in the upper right hand corner of Figure 7. If a user is a member of the Shift Supervisor, Remote Manager Node or System Engineer user groups, then each individual temperature indication is shown as a green or blue colored bar. If the bar is blue then the temperature for that point is included in the average--if it is green it is not included. Only Shift Supervisor or System Engineer users can change the averaging. NOTE: Multiple trending windows may be opened at one time, but is limited to a maximum of three. 


\section{User Manual for AZ-101 Data Acquisition System}

\subsubsection{Micon Data}

This screen displays ventilation process data for TK AZ-101. Primary data available as shown in Figure 8 are:

$>$ Ventilation Temperature

$>$ Heater Differential Pressure Heater

$>$ Tank Pressure

$>$ Radiation Level

$>$ Filter Differential Pressure

$>$ Stack Flow

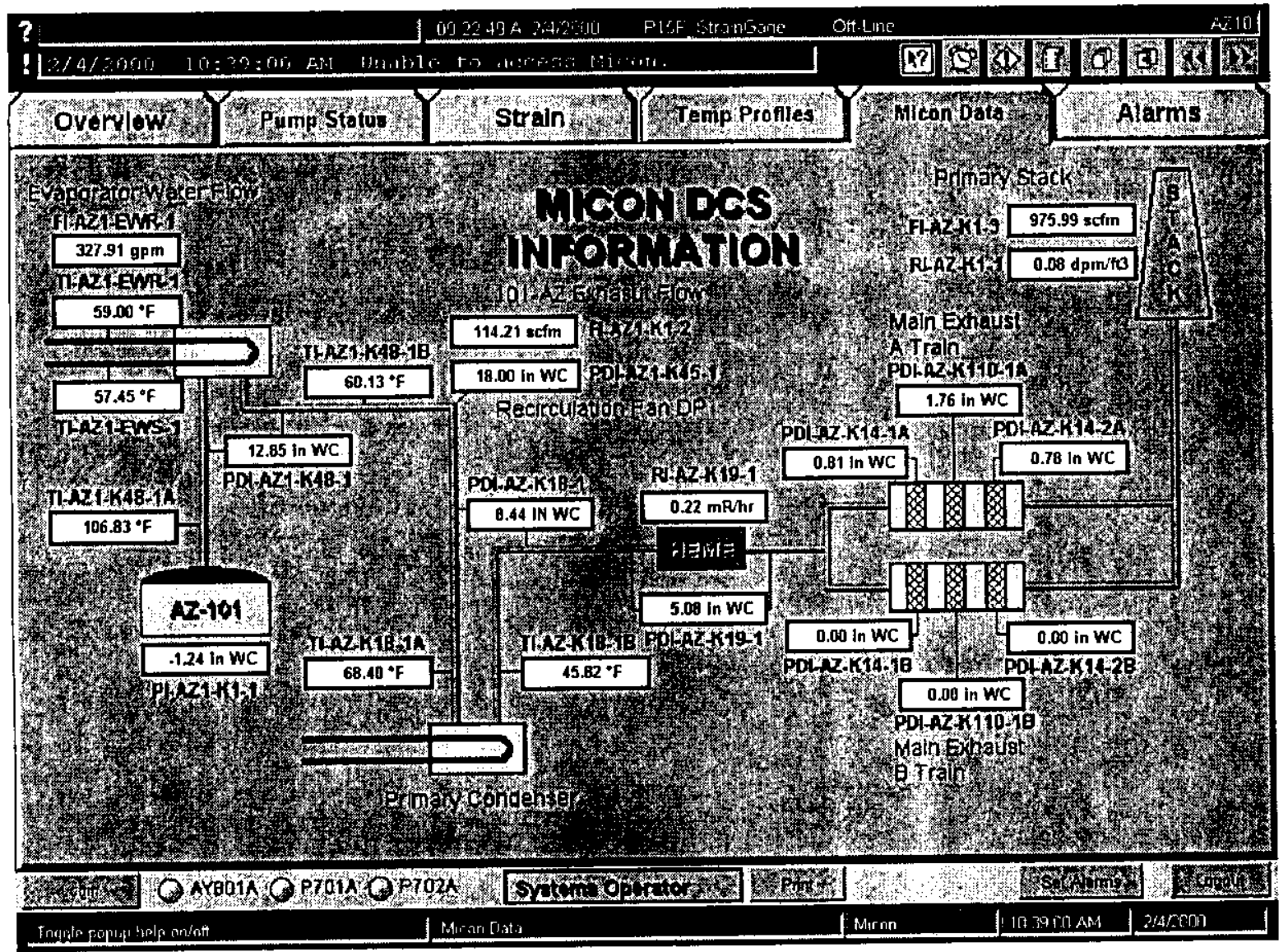

FIGURE 8 


\section{User Manual for AZ-101 Data Acquisition System}

\subsection{Alarms}

This screen, shown in Figure 9, displays several alarm conditions depending on the alarm icon chosen from the vertical alarm icons menu at the right. You can also use the "Enable/Disable" button to individually, or globally enable and disable alarms. Select this button, and choose a tag name from the scroll list and choose the "Enable" or "Disable" button depending on the current status of that tag. To view status use the "View All, "View Active" and "View Disabled" buttons. To close, select the "Close Button".

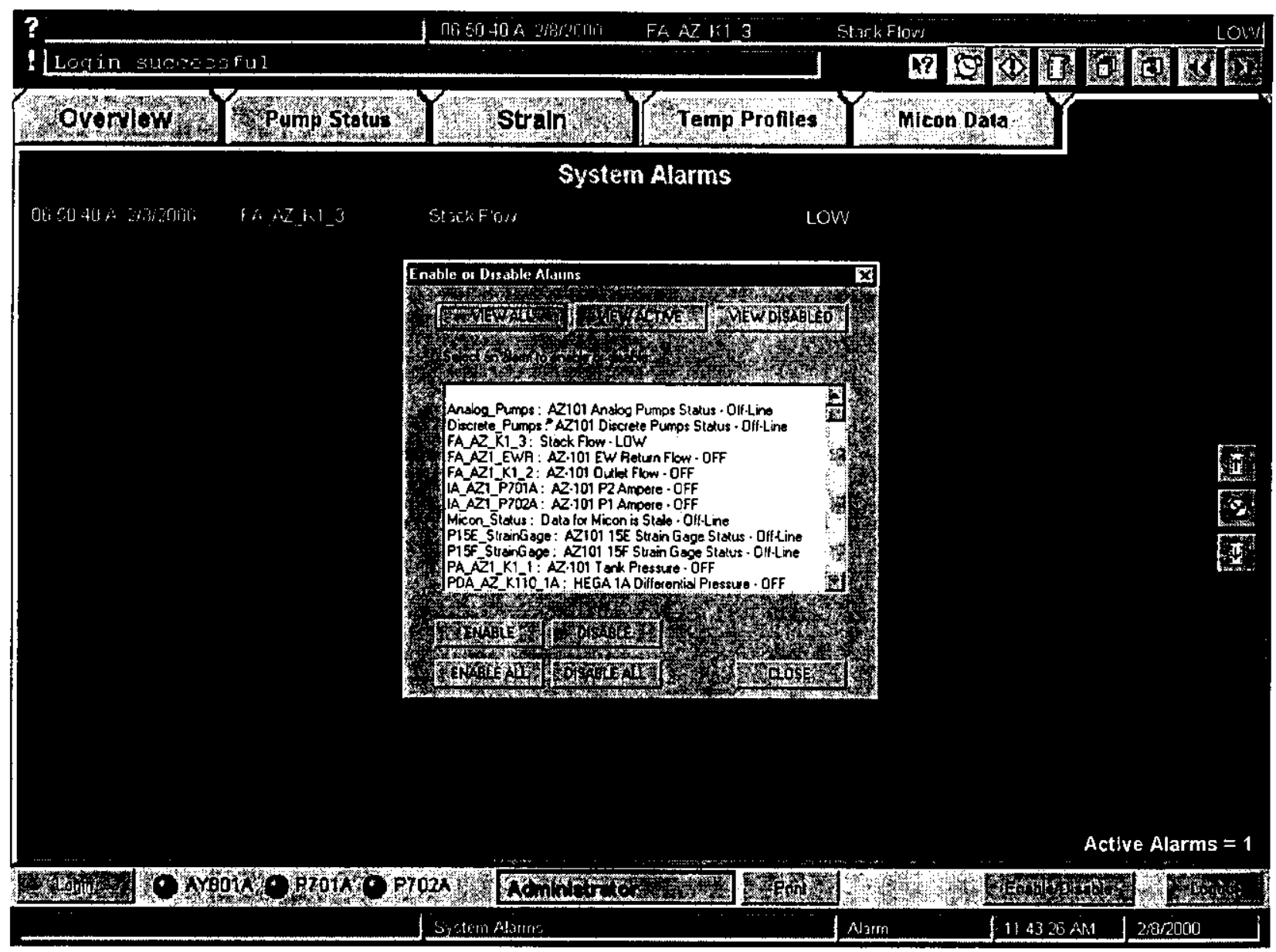

FIGURE 9 


\subsubsection{Alarm Icons}

The alarm icons are available from any parent screen to expedite user response to alarms. When an icon is selected the associated screen is displayed as described below:

$>$ Alarm Clock Icon--displays the same Systems Alarm screen which is any active alarm.

Exclamation Point in a Diamond Icon--displays the Hardware Alarm screen.

$>$ Scroll of Paper--displays the Alarm Summary Screen for up to the last 1000 events.

$>$ Alarm Clock w/Slash Icon--If animated, disabled alarms are present for viewing (alarms may only be enabled/disabled by user with Supervisor privileges and above).

The vertical icons described below appear only on the actual alarm screens (center right):

$>$ Alarm Clock with Check Mark--acknowledges all alarms displayed on page.

$>$ Scrolled Paper with Up Arrow--scrolls up through alarms.

$>$ Scrolled Paper with Down Arrow--scrolls down through alarms.

\subsubsection{Acknowledging Alarms}

Alarms give a visual indication via 1) changing color, 2) flashing, and 3) sounding a clanging echo through the HMI PC speaker system. Alarms are color coded as indicated in Table 3.

NOTE - The speakers used with the AZ-101 DAS are equipped with a volume control. Alarms may be silenced momentarily to discuss alarm response actions, but they should be restored to an audible level immediately afterwards.

\begin{tabular}{|c|c|}
\hline \multicolumn{2}{|c|}{ Table 3-Alarm Color Coding Scheme } \\
\hline ALARM LEVEL & COLOR \\
\hline High-High & RED \\
\hline High & RED \\
\hline Low & RED \\
\hline Low-Low & RED \\
\hline
\end{tabular}


Acknowledging alarms, by going to the "ALARMS" screen and clicking on the active alarm clears the alarm sound. However if the data value is still out of range the color of the data box remains per the table above. If the alarm clears without being acknowledged, the alarm text will display as solid yellow. When acknowledged, an alarm's text will clear from the alarm screen, unless the alarm condition still exists, in which case the alarm text is shown as solid red.

For multiple alarms, select the "ACKNOWLEDGE ALL" button (Alarm Clock w/Checkmark Vertical Icon) to acknowledge all alarms that are displayed in the list. New unacknowledged alarms are automatically added to this list to be displayed to the user. 


\subsection{Trending Data}

Data can be trended in two ways: a single data point display, and a multiple data point trend exported to an Excel spreadsheet.

\subsubsection{Single Point Trend}

A trend for a single data point is available, on all parent screens except "Alarms". Position the mouse cursor on a data point's numeric display area and a white outline box will appear around this display area if the trend is available. Then left click the mouse and the result is as shown in Figure 10.

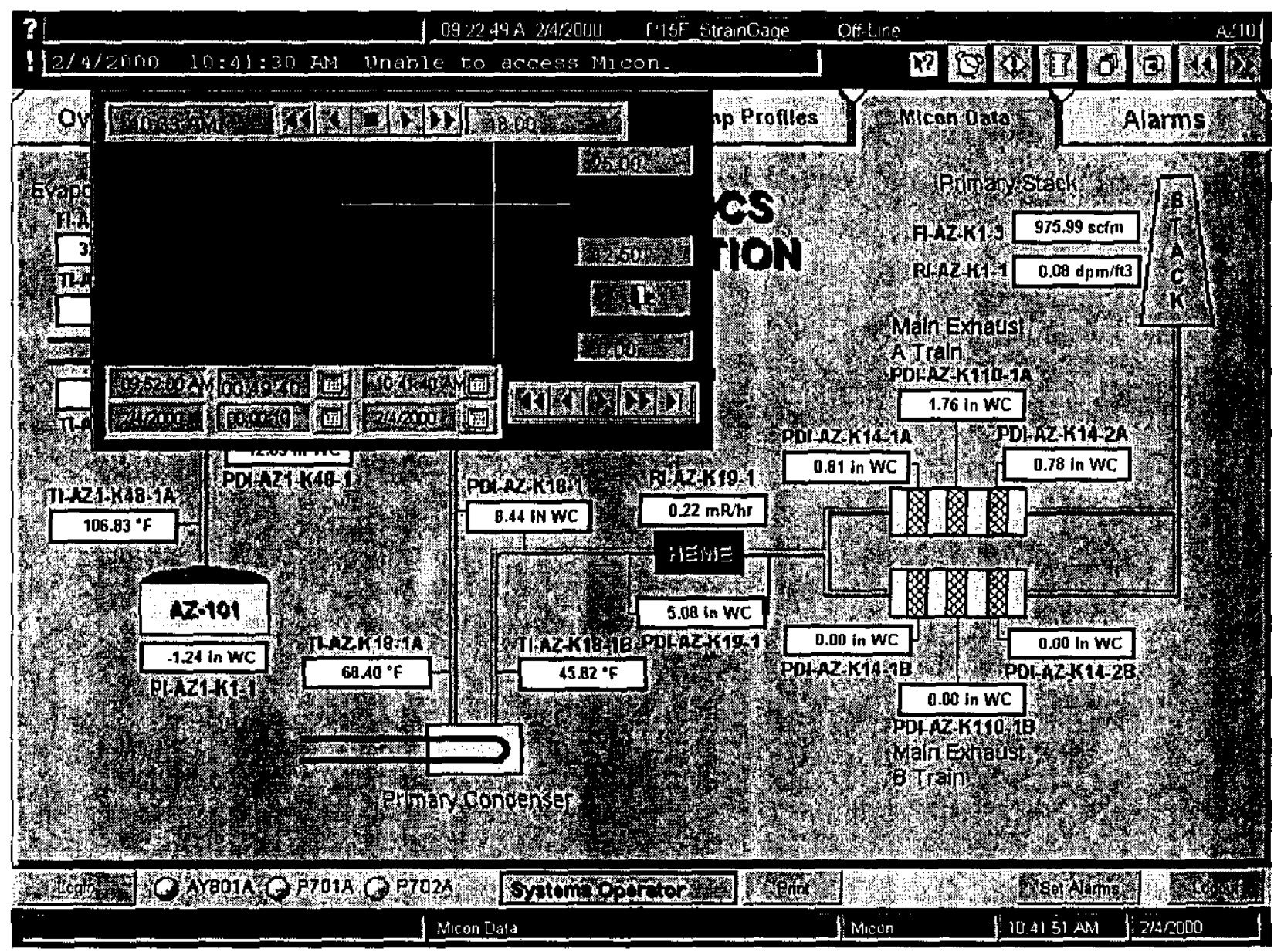

FIGURE 10 
Functions and control of this trend box are as follows:

- Horizontal window position: Click the arrow buttons at the bottom right of the screen to scroll the plot backward in time and view more historical data. Click the rightmost arrow (pictured below) to view the current data.

\section{[x/10[0]}

- Cursor Position: Use the arrow buttons in top center of screen to adjust the position of the cursor. (If cursor is not visible, click on the black area of the trend plot, or drag the cursor out from the right hand edge of the plot.)

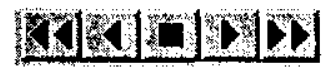

You may adjust the trending chart by using the group of icons shown below:

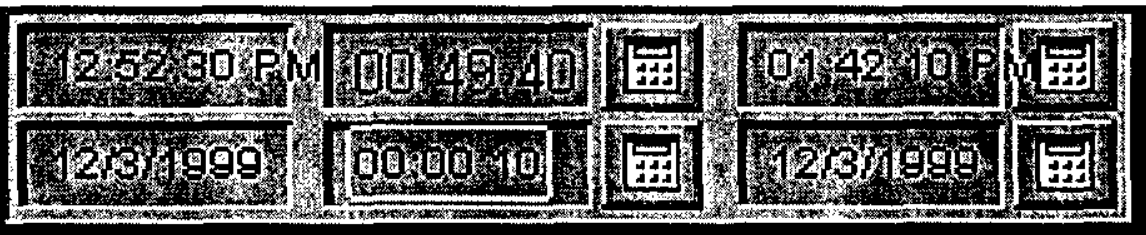

- Set Trend Time-Span: This adjusts the amount of data displayed between the left and right edges of the plot. Click the blue calculator icon (top left) which will display a number notepad. Enter a value in HH:MM:SS format by using either the keyboard or the mouse and click OK. The sample period is automatically readjusted.

- Set End Time: Select a time from which you want the trend to "look back". Click the blue calculator icon (top right), which will display a number notepad, and enter time. Enter values in HH:MM:SS, 24 hour format.

- Set Trend Time-Base: This determines the trend display resolution, or the amount of time for each "dot" on the graph. Click the blue calculator icon (bottom left), which will display a number notepad, and enter a value in HH:MM:SS format by using either the keyboard or the mouse, and click OK. The plot span is automatically readjusted.

- Set End Date: Select a date from which you want the trend to "look back". Click the blue calculator icon (bottom right), which will display a number notepad, and enter date values. Enter values in $\mathrm{HH}$ :MM:SS format. 
- Scale (vertical): Adjust the maximum and minimum scale values by placing the mouse pointer over the current minimum or maximum value and selecting. This will display a number keypad to allow the scale to be changed.

NOTE: The middle (50\%) scale value is automatically readjusted when the scale is changed

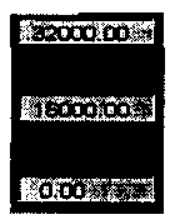

To Exit--Click on the "Exit Door" icon.

\subsubsection{Excel Trend Sets}

Operator level users and above can export all Citect data point trends to local Comma Separated Value (CSV) files for use with a Microsoft Excel spreadsheet for data graphing and trending from Excel. These files are stored in the $\mathrm{C}$ : drive under the subdirectory "C: $\backslash W 151 \backslash . . . "$ (there are several options for data trends). A typical Excel spreadsheet is shown in Figure 11. The use of Excel to perform these functions is outside the scope of this document. Consult your Excel user's manual. To perform this function, from the "OVERVIEW" screen select the "Update All Trend Files" button on the far right-hand side of this screen. One week per update file of data is available, and the number of update files is only limited by the system hard disk capacity. This update should be performed consistently, once a week to ensure optimal performance. The function will back-up previous data, and reset the current data trends and start logging new data.

NOTE: If you lose power while performing this function, the "Update All Trend Files" button will show as "grayed out" and therefore unavailable. Press CNTL-T in this case to enable the button and the function. 


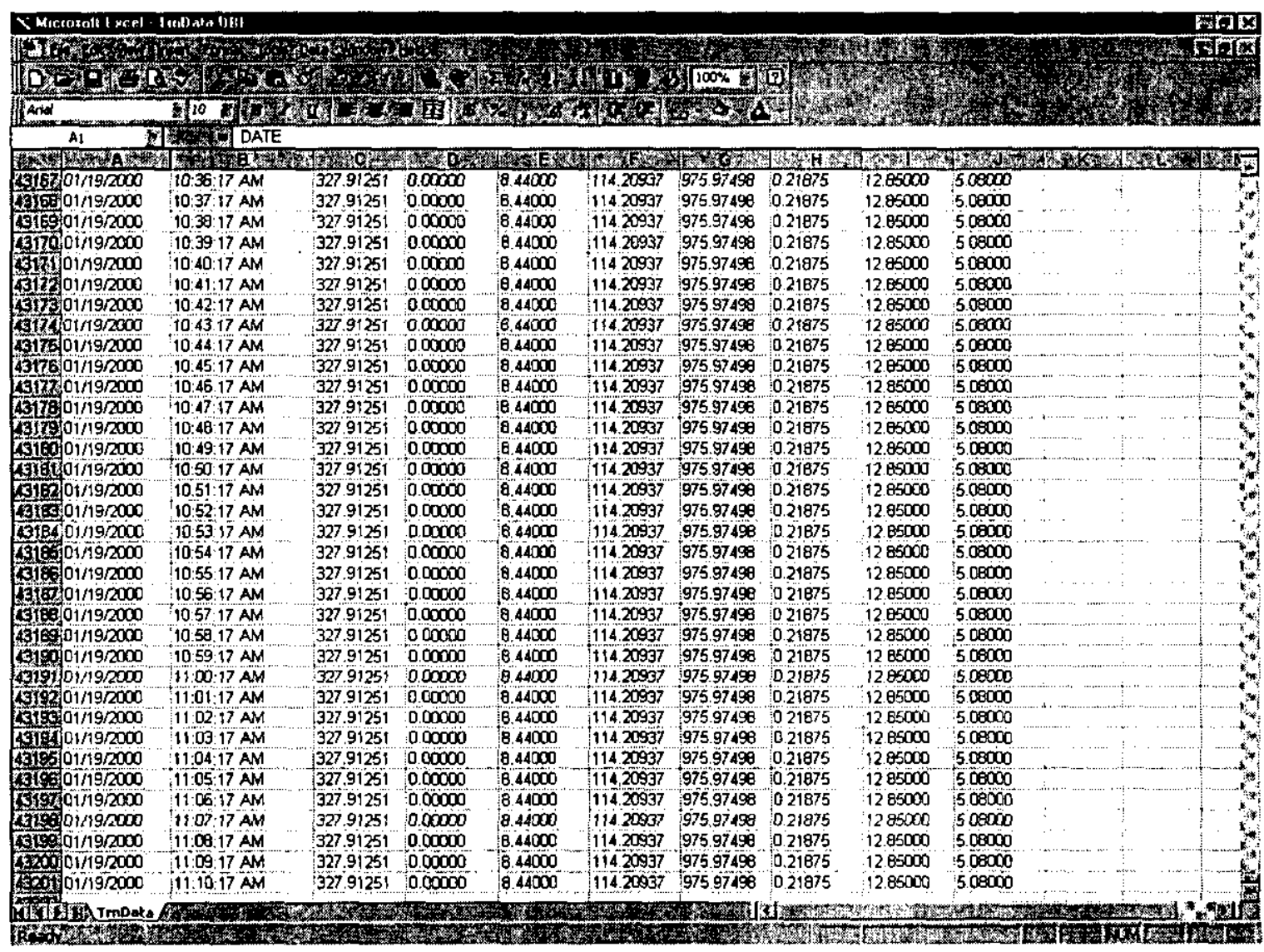

\section{FIGURE 11}

\subsection{Shutting Down}

To shut down the AZ-101 DAS software (does not shut down the PC), a user must be an Operator or above user group. Press the "Esc" key and click "Yes" if you are sure, or "No" to return. The PC shall then shut down the AZ-101 DAS HMI and return to native Windows NT. No other action is required. To restart the application, cycle the power on the HMI PC. 